\title{
Changes in tryptophan and phenylalanine in chronic HCV patients treated with direct acting antiviral (sofosbuvir)
}

\author{
Eman G. Behiry ${ }^{*}$, Sara K. Mahmoud ${ }^{2}$, Mohamed A. Swelim², Khaled A. El-dougdoug ${ }^{3}$, Attia A. A. ${ }^{2}$ \\ and Ahmed M. Hussein ${ }^{4}$
}

\begin{abstract}
Background: Chronic hepatitis $\mathrm{C}$ virus (HCV) infection represents a global public health challenge, and new drugs have been authorized for its treatment. The current study aimed to detect the change in blood levels of tryptophan and phenylalanine with the recent therapy direct-acting antiviral (sofosbuvir).

Methods: This case-controlled study was conducted on HCV patients including 40 treated with direct-acting antiviral (sofosbuvir), 40 untreated underestimations of full medical history, and laboratory tests involved ELISA assay and real-time (RT) PCR technique as well as measuring tryptophan and phenylalanine by HPLC-UV, in addition to 20 apparently healthy subjects served as a control group.

Results: There is a high statistical significant decrease in tryptophan and increase in phenylalanine in treated cases than untreated cases and control groups. This study showed that phenylalanine at the cutoff of $2.13 \mu \mathrm{g} / \mathrm{ml}$ had 96 . $9 \%$ sensitivity and $62.5 \%$ specificity among treated cases; also, tryptophan at the cutoff of $8.53 \mathrm{ng} / \mathrm{ml}$ had $81.2 \%$ sensitivity and $75 \%$ specificity to predict severe depression. There is a statistically significant increase in tryptophan and decrease in phenylalanine in mild/moderate than very severe depression.

Conclusion: Direct-acting antiviral (sofosbuvir) causes a decrease in tryptophan levels and increase in phenylalanine levels that as a result leading to depressive symptoms as adverse effects, so advising by dietary supplements of tryptophan for patients treated from chronic HCV by direct-acting antiviral (sofosbuvir).
\end{abstract}

Keywords: Tryptophan, Phenylalanine, Sofosbuvir

\section{Introduction}

One of the countries most affected by HCV is Egypt. The Egypt Demographic and Health Surveys (EDHS) measured antibody prevalence among the adult population aged $15-59$ years at $14.7 \%$ in 2009 and at $10.0 \%$ in 2015 (Kandeel et al. 2017).

The most effective initial therapy for patients was peg interferon in combination with ribavirin. With this two-drug regimen, about $40 \%$ of patients achieve a sustained virological response (SVR) (Razavi et al. 2014; McHutchison et al. 1998). Current treatment of chronic $\mathrm{HCV}$ is direct-acting antiviral (sofosbuvir included or

\footnotetext{
* Correspondence: emangamal24@yahoo.com

${ }^{1}$ Clinical and Chemical Pathology Department, Benha Faculty of Medicine,

Benha University, Benha 13015, Egypt

Full list of author information is available at the end of the article
}

sofosbuvir-free protocol) proven to be the best treatment for $\mathrm{HCV}$ infection giving an efficacy of $95 \%$ (Osinusi et al. 2013).

The mechanism of action of sofosbuvir by inhibiting the viral protein replication (nonstructural protein) is considered as NS5B inhibitors (Pfaender et al. 2016; Pan et al. 2016). Tryptophan is essential amino acids, used as building blocks in protein biosynthesis, and proteins are required to sustain life (Kumar et al. 2009). Tryptophan plays special roles in "anchoring" membrane proteins within the cell membrane. In addition, tryptophan functions as a biochemical precursor serotonin, melatonin, niacin, and auxins (Stepanova et al. 2008).

Phenylalanine is a precursor for tyrosine, monoamine neurotransmitters dopamine, norepinephrine (noradrenaline), 
and epinephrine (adrenaline), and the skin pigment melanin (Sajadi 2011). The interferon proved to have depressed symptoms by decreasing tryptophan level and increasing phenylalanine level (Zoller et al. 2012).

Direct-acting antiviral (sofosbuvir) can cause an alteration of the tryptophan (try) level, and also, the essential amino acid phenylalanine (Phe) has been observed in patients suffering from inflammatory conditions and a consequently reduced synthesis of serotonin. The interferon proved to have depressed symptoms by decreasing tryptophan level and increasing phenylalanine level (Kattakuzhy et al. 2015).

The current study is a novel study first to be done in Egypt, aimed to investigate the effect of therapy direct acting antiviral (sofosbuvir) on the change of blood levels of tryptophan and phenylalanine that could be detected by HPLC-UV on the development of depression in treated and untreated patients affected by chronic $\mathrm{HCV}$.

\section{Subjects and methods Subjects}

This case-controlled study was conducted on $80 \mathrm{HCV}$ patients attending Internal Medicine Department at Benha University Hospitals in addition to (Oxenkrug et al. 2014) apparently healthy subjects served as control group from January 2016 to May 2017. Laboratory work was done in the Clinical and Chemical Pathology Department; subjects were classified into three groups as follows:

Group I-included 40 patients with $\mathrm{HCV}$ under treatment.

Group II-included 40 patients with $\mathrm{HCV}$ before treatment.

Group III-included (Oxenkrug et al. 2014) apparently healthy individuals (control group).

Diagnosis of chronic $\mathrm{HCV}$ depends on $\mathrm{HCV} \mathrm{Ab}$ positive $>6$ months.

\section{Ethical approval}

This study protocol was approved by an ethical review board of Benha University. Written informed consent was obtained from each patient included in the study. The study protocol is according to the World Medical Association Declaration of Helsinki (Idänpään-Heikkilä 2001).

Inclusion criteria The following are the inclusion criteria:

1. Patients $>18$ years old

2. Patients with liver cirrhosis

3. Patients with HCV (confirmed by serological tests and PCR)
Exclusion criteria The following are the exclusion criteria:

1. Patients $<18$ years old

2. Other causes of liver cirrhosis other than chronic $\mathrm{HCV}$ infection (HBV, autoimmune cirrhosis, biliary cirrhosis)

\section{Methods}

All participants were subjected to the following:

1. Full history taking and clinical examination.

2. Hamilton Rating Scale for Depression (HDRS Scale) is a multiple item questionnaire used to provide an indication of depression and as a guide to evaluate recovery (HDRS-17 n.d.). A score of 0-7 is generally accepted to be within the normal range, while a score of 20 or higher indicates at least moderate severity.

3. Laboratory investigation including:

(a) Sampling-6 $\mathrm{mm}$ of venous blood was drawn under aseptic conditions and distributed as follows.

i. -Complete liver functions (ALT, AST, bilirubin and Albumin

ii. -Quantitative detection of HCV by Real-time PCR technique.

Principle-TaqMan real-time PCR assays consist of target-specific primers and one or more probes optimized for specific types of measurements. TaqMan probes consist of a fluorophore covalently attached to the 5 '-end of the oligonucleotide probe and a quencher at the $3^{\prime}$-end (Arya et al. 2005).

iii. -Plasma level of tryptophan and phenylalanine.

\section{(b) Principle}

The sample vials were contained in $50 \mu$ of the internal standard, and the calibrator was reconstituted. The vials were mixed briefly on a vortex mixer. The sample vials were lifted for $15 \mathrm{~min}$ at $2-8{ }^{\circ} \mathrm{C}$ then centrifuged at $10.000 \mathrm{~g}$ for $5 \mathrm{~min} ; 20 \mu \mathrm{l}$ of the supernatant was injected for chromatography column (Eagle column (IC4000rp with $125 \mathrm{~mm} \times 4 \mathrm{~mm}$ ) into the HPLC-system with UV detector at $210 \mathrm{~nm}$ for $10 \mathrm{~min}$ at $30{ }^{\circ} \mathrm{C}$. Before use, the system was equilibrated with ca. $30 \mathrm{ml}$ ELU. Phenylalanine tryptophan HPLC assay 6/10 catalog number: PNL31-H100 www.EagleBio.com using HPLC Hewlett Packard 1100 instrument, Japan. 
Table 1 Comparing the studied groups regarding liver function tests

\begin{tabular}{|c|c|c|c|c|c|c|c|c|c|c|c|}
\hline \multirow[t]{2}{*}{ Variable } & \multicolumn{3}{|c|}{ Untreated HCV cases $(n=40)$} & \multicolumn{3}{|c|}{ Treated HCV cases $(n=40)$} & \multicolumn{3}{|c|}{ Controls $(n=20)$} & \multirow[t]{2}{*}{ KW test } & \multirow[t]{2}{*}{$p$} \\
\hline & Mean & $\pm \mathrm{SD}$ & Range & Mean & $\pm \mathrm{SD}$ & Range & Mean & $\pm \mathrm{SD}$ & Range & & \\
\hline Age (years) & 45.8 & 11.0 & $22-65$ & 51.5 & 12.2 & $32-77$ & 46.1 & 12.6 & $20-67$ & ANOVA 2.66 & 0.075 (NS) \\
\hline $\operatorname{ALT}(\mathrm{U} / \mathrm{l})$ & 24.7 & 7.54 & $13-37$ & 28.3 & 11.56 & $13-51$ & 18.9 & 6.02 & $10-33$ & 9.42 & $0.009(S)$ \\
\hline AST $(U / \mathrm{l})$ & 28.9 & 8.28 & $19-44$ & 36.6 & 11.03 & $20-60$ & 25.8 & 6.69 & $16-38$ & 17.8 & $<0.001(\mathrm{HS}$ \\
\hline Albumin (g/dl) & 3.95 & 0.66 & $2.1-5.1$ & 3.90 & 0.64 & $2.2-4.9$ & 4.13 & 0.50 & $3.6-5.1$ & 0.62 & 0.73 (NS) \\
\hline Total bilirubin (mg/dl) & 1.01 & 0.44 & $0.6-2.22$ & 0.98 & 0.42 & $0.6-2.3$ & 0.75 & 0.11 & $0.56-0.92$ & 5.25 & 0.072 (NS) \\
\hline Direct bilirubin (mg/dl) & 0.28 & 0.26 & $0.1-0.97$ & 0.26 & 0.18 & $0.11-0.92$ & 0.15 & 0.04 & $0.1-0.21$ & 7.22 & $0.027(\mathrm{~S})$ \\
\hline
\end{tabular}

KW Kruskal-Wallis test, NS non significant, $S$ significant, $H S$ highly significant

(c) Calculation of analytical results

Conc. sample $(\mathrm{mg} / \mathrm{dl})=$ peak area patient $\times$ conc. calibrator $(\mathrm{mg} / \mathrm{dl}) \times F /$ peak area IS patient.

$F=$ calibrator the of IS area peak/peak area analyte of the calibrator.

\section{Statistical analysis}

Data were analyzed using the statistical program for social sciences, SSPS version 18.0 (Chicago, USA). Quantitative data were expressed as mean $\pm S D$, and qualitative data were expressed as frequency and percentage. Independent samples $t$ test of significance was used when comparing two means; receiver operating characteristic (ROC) curve analysis was used to find the overall predictivity of parameters and find the best cutoff value for detection; along with sensitivity and specificity, univariant analysis was performed for each variable followed by multivariate analysis to detect factors predictors for depression. The Mann-Whitney $U$ test was used to compare two nonparametric quantitative variables $p<0.05$ was considered statistically significant.

\section{Results}

There is no statistically significant difference between the three groups regarding age or sex. All results of liver function tests are present in Table 1. There are eight cases with a low quantitative level of HCV-RNA in the treated group, 11 cases with intermediate viremia, 20 with high viral load, and 1 with very high viral load (mean $21.55 \times 10^{5}$ with Std. deviation of 27.25). On the other hand, the viral load in the untreated case was mean $127.1 \times 10^{5}$ with Std. deviation of 57.0. There are eight cases with D.M, another eight cases with D.M. associated with hypertension, four cases with diabetes and obesity, and two cases with ischemic heart disease associated with hypertension.

There is a high statistical significant decrease in tryptophan in treated cases than untreated cases and control groups applying post hoc test (Bonferroni test). On the other hand, there is a high statistical significant increase in phenylalanine in treated cases than control and untreated groups. There is a high statistical significant increase in HDRS in treated cases (34.7 \pm 9.37$)$ than untreated cases $(6.5 \pm 5.3)$ and control group $(3.0 \pm 3.89)$, Table 2.

There is a statistically significant difference between studied groups regarding the severity of depression. There is a statistically significant increase in tryptophan and decrease in phenylalanine in mild/moderate than very severe depression Table 3.

There is a negative correlation between HDRS Scale and tryptophan level and a positive correlation between HDRS Scale and phenylalanine level in the treated group. Fig. 1a, b.

This study showed that phenylalanine among treated cases at the cutoff value of $2.13 \mu \mathrm{g} / \mathrm{ml}$ had a sensitivity of $96.9 \%$, a specificity of $62.5 \%$, and area under the curve $=0.848$ to predict severe depression. Also, tryptophan levels among treated cases at a cutoff value of $8.53 \mathrm{ng} / \mathrm{ml}$ had a sensitivity of $81.2 \%$, a specificity of $75 \%$, and area under the curve $=0.812$ to predict severe depression Table 4 and Fig. 2.

Table 2 Comparing the studied groups regarding amino acids

\begin{tabular}{|c|c|c|c|c|c|c|c|c|c|c|c|}
\hline \multirow[t]{2}{*}{ Variable } & \multicolumn{3}{|c|}{ Untreated HCV cases $(n=40)$} & \multicolumn{3}{|c|}{ Treated HCV cases $(n=40)$} & \multicolumn{3}{|c|}{ Controls $(n=20)$} & \multirow{2}{*}{$\begin{array}{l}\mathrm{KW} \\
\text { test }\end{array}$} & \multirow[t]{2}{*}{$p$} \\
\hline & Mean & $\pm S D$ & Range & Mean & $\pm S D$ & Range & Mean & $\pm \mathrm{SD}$ & Range & & \\
\hline Tryptophan ( $\mu \mathrm{g} / \mathrm{ml})$ & 12.8 & 0.66 & $11.9-14.45$ & 7.08 & 2.46 & $3.42-12.22$ & 12.8 & 0.55 & $3.42-13.9$ & 69.9 & $<0.001(\mathrm{HS})$ \\
\hline Phenylalanine (ng/ml) & 1.23 & 0.41 & $0.57-2.24$ & 2.46 & 0.29 & $2.07-2.99$ & 0.93 & 0.31 & $0.41-1.51$ & 71.9 & $<0.001(\mathrm{HS})$ \\
\hline HDRS & 6.5 & 5.30 & $0-24$ & 34.7 & 9.37 & $13-50$ & 3.0 & 3.89 & $0-16$ & 73.8 & $<0.001(\mathrm{HS})$ \\
\hline
\end{tabular}


Table 3 Amino acids levels according to severity of depression among the treated group

\begin{tabular}{|c|c|c|c|c|c|c|c|c|c|c|c|}
\hline \multirow[t]{2}{*}{ Variable } & \multicolumn{3}{|c|}{ Mild/moderate $(n=4)$} & \multicolumn{3}{|c|}{ Severe $(n=4)$} & \multicolumn{3}{|c|}{ Very severe $(n=32)$} & \multirow{2}{*}{$\begin{array}{l}\text { KW } \\
\text { test }\end{array}$} & \multirow[t]{2}{*}{$p$} \\
\hline & Mean & $\pm \mathrm{SD}$ & Range & Mean & $\pm \mathrm{SD}$ & Range & Mean & $\pm \mathrm{SD}$ & Range & & \\
\hline Tryptophan ( $\mathrm{gg} / \mathrm{ml})$ & 9.34 & 3.77 & $3.79-12.2$ & 8.87 & 0.80 & 7.89-9.6 & 6.57 & 2.20 & $3.42-11.58$ & 7.32 & $0.026(\mathrm{~S})$ \\
\hline Phenylalanine (ng/ml) & 2.09 & 0.02 & $2.07-2.13$ & 2.34 & 0.17 & $2.12-2.55$ & 2.52 & 0.28 & $2.11-2.99$ & 11.4 & $0.003(S)$ \\
\hline
\end{tabular}

$S$ significant

Applying multiple linear regression analysis, blood phenylalanine and tryptophan levels are significant ( $p<0.05$ for both) predictors of HDRS among treated group Table 5 .

\section{Discussion}

Peg IFN proved to have depressive symptoms in chronic $\mathrm{HCV}$ patients by altering levels of tryptophan and phenylalanine. Also, our study proved that direct-acting antiviral (sofosbuvir) has the same side effects, as the two therapies having the same mechanism.

This study showed that increasing phenylalanine among treated cases at a cutoff of $2.13 \mu \mathrm{g} / \mathrm{ml}$ phenylalanine had $96.9 \%$ sensitivity, $62.5 \%$ specificity, and area under the curve of 0.848 with significant $p$ value $(0.003)$ to predict severe depression. Also, decreasing tryptophan levels among treated cases at a cutoff of $8.53 \mathrm{ng} / \mathrm{ml} \mathrm{had}$ $81.2 \%$ sensitivity, $75 \%$ specificity, and area under the curve of 0.812 with significant $p$ value of 0.007 to predict severe depression. Yang et al. found that with a bad prognosis of liver cirrhosis in HCV patients to hepatocellular carcinoma, the IDO level increases and converts tryptophan to kynurenine, so decreasing tryptophan level according to the fibrotic degree without the antiviral therapy, which is in contrast with our results (Yang et al. 2018).

Also Mehraj and Routy reported that in a chronic viral infection that was not cleared during acute infection highjacks the host immune response to create a state of disease tolerance via kynurenine catabolites via IDO-mediated pathway of tryptophan, so that confirming the hypothesis that kynurenine causing
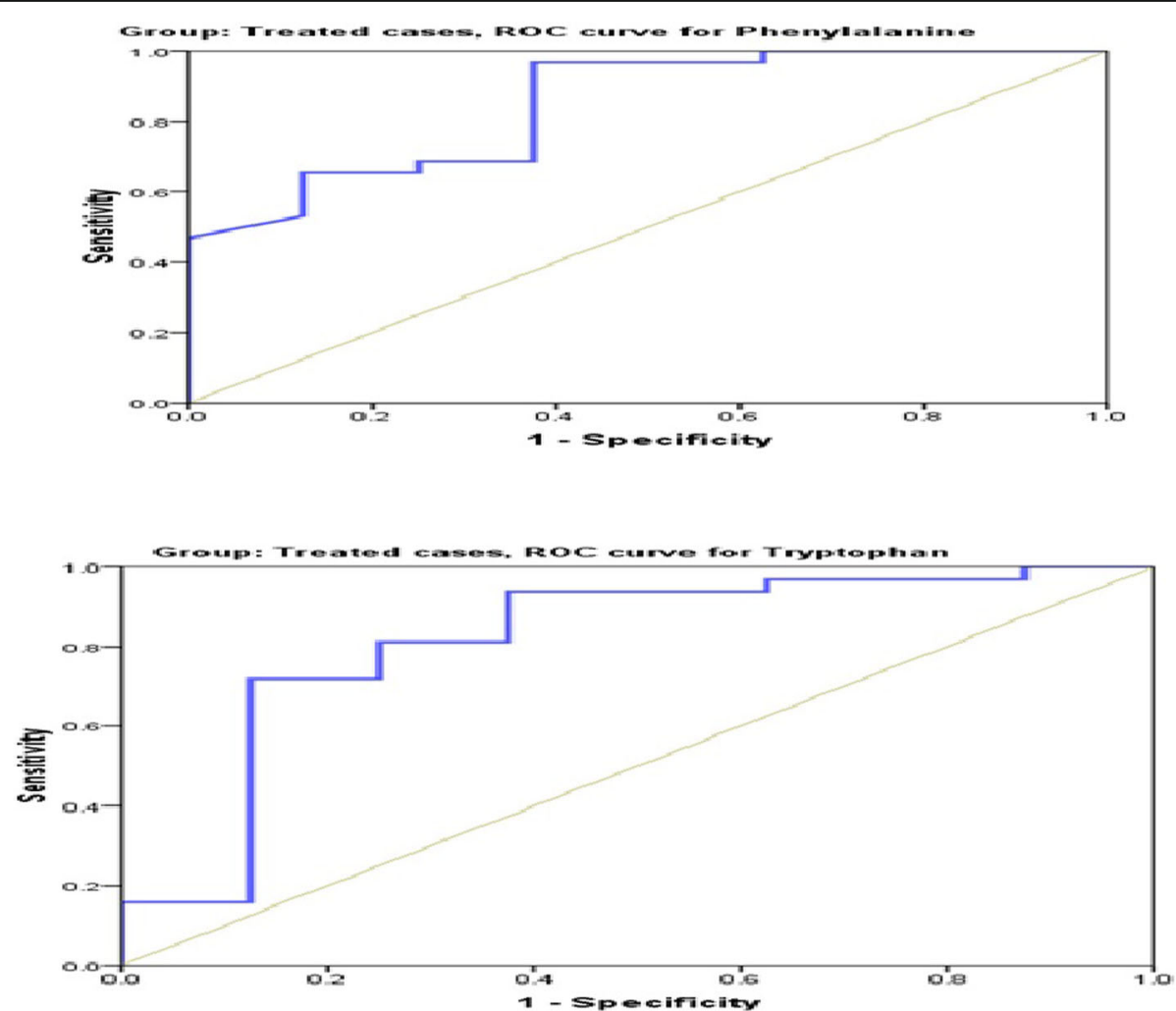

Fig. 1 Scatter graph showing a positive correlation between phenylalanine level and HDRS and $\mathbf{b}$ negative correlation between tryptophan level and HDRS 
Table 4 ROC curve for the performance of amino acids in the prediction of very severe depression among the treated cases

\begin{tabular}{lllllllll}
\hline Score & Sens $\%$ & Spec $\%$ & PPV $\%$ & NPV $\%$ & Accuracy \% & AUC & $95 \% \mathrm{Cl}$ & P \\
\hline Phenylalanine $\geq 2.13 \mu \mathrm{g} / \mathrm{ml}$ & 96.9 & 62.5 & 91.1 & 83.3 & 92.5 & 0.848 & $0.7-0.99$ & $0.003(\mathrm{~S})$ \\
Tryptophan $\leq 8.53 \mathrm{ng} / \mathrm{ml}$ & 81.2 & 75 & 92.8 & 50 & 80 & 0.812 & $0.62-1.0$ & $0.007(\mathrm{~S})$ \\
\hline
\end{tabular}

$S$ significant

immunosuppression to the host (Mehraj and Routy 2015). Another result is done by Murakami et al. that agree with our result that reported IDO gene deletion in mice leading to increasing destruction of tryptophan ( $\downarrow$ level) and that resulting in $(\uparrow)$ kynurenine and low serotonin level leading to high degree of depression (Murakami et al. 2016).

Also, the previous results confirmed that result which is done by Zoller.et al. who reported that viral IL28B polymorphism with $\mathrm{C} / \mathrm{C}$ genotype in chronic $\mathrm{HCV}$ patients showed that highest rate of tryptophan destruction with kynurenine production (high KYN/TRP ratio) leading to immunosuppression, and $\mathrm{T} / \mathrm{T}$ genotype showed the lowest rate (Zoller et al. 2015).

As our result proved that lowering tryptophan and increasing phenylalanine causing different depression degrees by using HDRS that study agreed with result done by Comai et al. who confirmed that increased IDO-mediated TRP metabolism along kynurenine pathway leading to TRP depletion and a decline of serotonin pathway leading to development of depressive symptoms observed in $\mathrm{HCV}$ patients undergoing IFN- $\alpha$ therapy, concluding that the antiviral therapy causing depressive symptoms via a long pathway starting with tryptophan amino acid as a precursor (Comai et al. 2011).
Also, our result agrees with the result done by Oxenkrug et al., who reported that the elevated tryptophan level may reflect the impairment of tryptophan conversion into serotonin in agreement with the suggested link between serotonin deficiency and depression. So, upregulation of IDO might be an additional risk factor of IFN- $\alpha$-associated depression. This study confirms that antiviral therapy (IFN- $\alpha$ ) causes depression by increasing IDO level that destructs TRP and lowers serotonin (Oxenkrug et al. 2014).

That result can be confirmed again by Loftis et al., results who reported that baseline serotonin level, in combination with other variables such as liver fibrosis degree, may be clinically useful for identifying patients in whom HCV can be cleared by antiviral therapy (Loftis et al. 2010), and that also can be explained by Messaoud et al., who reported that the reduced availability of TRP for serotonin synthesis and increased activation of KYN pathway and cortisol correlate with depression and suicide, so low tryptophan levels may be a biomarker of major depressive disorder (MDD) and suicide in MDD (Messaoud et al. 2018).

Also, Saleem et al.'s results agree with our study reporting that increasing TRP and brain serotonin metabolism change diet-restriction-induced behaviors
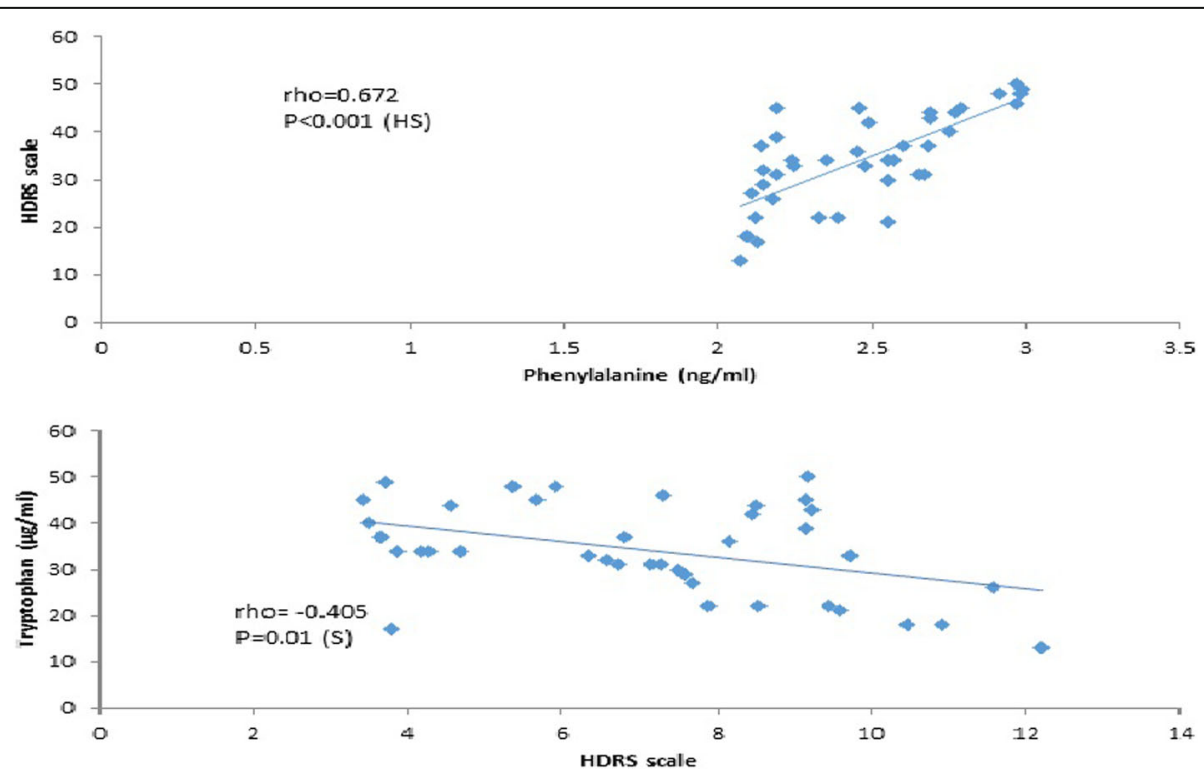

Fig. 2 ROC curve for the performance of phenylalanine (a) and tryptophan (b) in the prediction of very severe depression among the treated cases 
Table 5 Multiple linear regression for the predictors of HDRS scale of depression among the treated group

\begin{tabular}{|c|c|c|c|c|c|c|}
\hline \multirow[t]{2}{*}{ Model summary } & \multicolumn{2}{|l|}{$R^{2}$} & Adjusted $R^{2}$ & SEE & $F$ & $p$ value \\
\hline & \multicolumn{2}{|l|}{0.553} & 0.529 & 6.8 & 22.9 & $<0.001(\mathrm{HS})$ \\
\hline \multirow[t]{2}{*}{ Variable } & \multicolumn{2}{|c|}{ Unstandardized coefficients } & Standardized coefficients & $95 \% \mathrm{Cl}$ of $\mathrm{B}$ & $t$ & $p$ \\
\hline & $B$ & Std. error & Beta & & & \\
\hline (Constant) & -15.05 & 6.4 & - & -38.2 to -8.1 & 3.37 & $<0.001(\mathrm{HS})$ \\
\hline Phenylalanine & 22.2 & 3.79 & 0.655 & 14.1 to 30.2 & 5.59 & $<0.001(\mathrm{HS})$ \\
\hline Tryptophan & -5.78 & 0.47 & -0.294 & -7.74 to -1.75 & 2.15 & $0.031(S)$ \\
\hline
\end{tabular}

$S$ significant, $H S$ highly significant

such as depression, anxiety, and anorexia nervosa (AN). So, they conclude that diet-restriction-induced behavioral changes might be reverted back with the administration of TRP and helpful to improve psychological problems in AN (Saleem et al. 2018).

Also, Zignego et al.'s results agree with our result stating that HCV patients have reduced $(-28 \%)$ TRP levels and confirming that they frequently suffer from anxiety and depression-related symptoms (Zignego et al. 2007).

\section{Conclusion}

Direct-acting antiviral (sofosbuvir) causes a decrease in tryptophan levels and increase in phenylalanine levels that as a result leading to depressive symptoms as adverse effects, so advising by dietary supplements of tryptophan for patients treated from chronic $\mathrm{HCV}$ by direct-acting antiviral (sofosbuvir).

\section{Acknowledgements}

All authors are grateful to all patients who participated in this study.

\section{Funding}

No fund available.

\section{Availability of data and materials}

All materials and data are available and cheap.

\section{Authors' contributions}

EGB, SKM, and MAS have substantial contributions to the conception and design of the work and acquisition of data, drafted the work, approved the final version to be published, and agreed to be accountable for all aspects of the work in ensuring that questions related to the accuracy or integrity of any part of the work are appropriately investigated and resolved. EGB, AAA, $\mathrm{KAE}$, and $\mathrm{AMH}$ have substantial contributions to the statistical analysis and interpretation of data, drafted the work and revised it critically for important intellectual content, approved the final version to be published, and agreed to be accountable for all aspects of the work in ensuring that questions related to the accuracy or integrity of any part of the work are appropriately investigated and resolved. All authors read and approved the final manuscript.

\section{Ethics approval and consent to participate}

An approval from the Research Ethics Committee in Banha Faculty of Medicine was obtained according to the World Medical Association Declaration of Helsinki.

\section{Consent for publication}

All authors state that they all want to publish this paper in Bulletin of the National Research Centre.
Competing interests

The authors declare that they have no competing interests.

\section{Publisher's Note}

Springer Nature remains neutral with regard to jurisdictional claims in published maps and institutional affiliations.

\section{Author details}

${ }^{1}$ Clinical and Chemical Pathology Department, Benha Faculty of Medicine, Benha University, Benha 13015, Egypt. ²Botany Department, Science Faculty, Benha University, Benha, Egypt. ${ }^{3}$ Microbiology Department, Agriculture Faculty, Ain Shams University, Cairo, Egypt. ${ }^{4}$ Internal Medicine Department, Benha Faculty of Medicine, Benha University, Benha, Egypt.

Received: 18 June 2018 Accepted: 29 October 2018

Published online: 09 November 2018

\section{References}

Arya M et al (2005) Basic principles of real-time quantitative PCR. Expert Rev Mol Diagn 5(2):209-219

Comai S, Cavalletto L, Chemello L, Bernardinello E, Ragazzi E, Costa CVL, Bertazzo A (2011) Effects of PEG-interferon alpha plus ribavirin on tryptophan metabolism in patients with chronic hepatitis C. Pharmacol Res 63(1):85-92

HDRS-17 (n.d.) Hamilton Depression Rating Scale (HDRS) at University of Florida College of Medicine. Additional questions retrieved December 12, 2011.

Idänpään-Heikkilä JE (2001) Ethical principles for the guidance of physicians in medical research: the Declaration of Helsinki. Bull World Health Organ 79(4):279-279

Kandeel A, Genedy M, El-Refai S, Funk AL, Fontanet A, Talaat M (2017) The prevalence of hepatitis C virus infection in Egypt 2015: implications for future policy on prevention and treatment. Liver Int 37(1):45-53

Kattakuzhy S, Levy R, Kottilil S (2015) Sofosbuvir for treatment of chronic hepatitis C. Hepatol Int 9(2):161-173

Kumar NS, Varghese S, Suresh CH, Rath NP, Das S (2009) Correlation between solid-state photophysical properties and molecular packing in a series of indane-1, 3-dione containing butadiene derivatives. J Phys Chem C 113(27):11927-11935

Loftis JM, Morasco BJ, Menasco D, Fuchs D, Strater M, Hauser P (2010) Serum serotonin levels are associated with antiviral therapy outcomes in patients with chronic hepatitis C. Open Infect Dis J 4:132

McHutchison JG, Gordon SC, Schiff ER, Shiffman ML, Lee WM, Rustgi VK, Albrecht JK et al (1998) Interferon alfa-2b alone or in combination with ribavirin as initial treatment for chronic hepatitis C. N Engl J Med 339(21):1485-1492

Mehraj V, Routy JP (2015) Tryptophan catabolism in chronic viral infections: handling uninvited guests. Int J Tryptophan Res 8:IJTR-S26862

Messaoud A, Rym M, Douki W, Neffati F, Najjar MF, Gobbi G et al. (2018) Reduced peripheral availability of tryptophan and increased activation of the kynurenine pathway and cortisol correlate with major depression and suicide. World J Biol Psychiatry 23:1-9.

Murakami Y, Ishibashi T, Tomita E, Imamura Y, Tashiro T, Watcharanurak K et al (2016) Depressive symptoms as a side effect of interferon-a therapy induced by induction of indoleamine 2, 3-dioxygenase 1. Sci Rep 6:29920

Osinusi A, Meissner EG, Lee YJ, Bon D, Heytens L, Nelson A et al (2013) Sofosbuvir and ribavirin for hepatitis $C$ genotype 1 in patients with unfavorable treatment characteristics: a randomized clinical trial. Jama 310(8):804-811 
Oxenkrug GF, Turski WA, Zgrajka W, Weinstock JV, Ruthazer R, Summergrad P (2014) Disturbances of tryptophan metabolism and risk of depression in HCV patients treated with IFN-alpha. J Infect Dis Ther 2(2):131-132.

Pan D, Niu Y, Xue W, Bai Q, Liu H, Yao X (2016) Computational study on the drug resistance mechanism of hepatitis C virus NS5B RNA-dependent RNA polymerase mutants to BMS-791325 by molecular dynamics simulation and binding free energy calculations. Chemom Intell Lab Syst 154:185-193

Pfaender S, Hahn T, Steinmann J, Ciesek S, Steinmann E (2016) Prevention strategies for blood-borne viruses-in the era of vaccines, direct acting antivirals and antiretroviral therapy. Rev Med Virol 26(5):330-339

Razavi H, Waked I, Sarrazin C, Myers RP, Idilman R, Calinas F et al (2014) The present and future disease burden of hepatitis $\mathrm{C}$ virus (HCV) infection with today's treatment paradigm. J Viral Hepat 21(s1):34-59

Sajadi SAA (2011) Complex bilding behavior of L-tryptophan and related amino acids, a comparative investigation. Am J Chem Soc 1(2):60-64

Saleem DM, Mehboob S, Khan MM, Samad N, Zafar A, Haleem DJ (2018) Inhibition of diet-restriction-induced behavioral deficits by tryptophan administration in rats. Pak J Pharm Sci 31 (3 (Supplementary)):1021-1029

Stepanova AN, Robertson-Hoyt J, Yun J, Benavente LM, Xie DY, Doležal K et al (2008) TAA1-mediated auxin biosynthesis is essential for hormone crosstalk and plant development. Cell 133(1):177-191

Yang R, Gao N, Chang Q, Meng X, Wang W (2018) The role of IDO, IL-10 and TGF- $\beta$ in the HCV-associated chronic hepatitis, liver cirrhosis, and hepatocellular carcinoma. J Med Virol https://doi.org/10.1002/jmv.25083

Zignego AL, Cozzi A, Carpenedo R, Giannini C, Rosselli M, Biagioli T et al (2007) HCV patients, psychopathology and tryptophan metabolism: analysis of the effects of pegylated interferon plus ribavirin treatment. Dig Liver Dis 39:S107-S111

Zoller H, Jenal A, Staettermayer AF, Schroecksnadel S, Ferenci P, Fuchs D (2015) Tryptophan breakdown in patients with HCV infection is influenced by IL28B polymorphism. Pharmaceuticals 8(2):337-350

Zoller H, Schloegl A, Schroecksnadel S, Vogel W, Fuchs D (2012) Interferon-alpha therapy in patients with hepatitis $C$ virus infection increases plasma phenylalanine and the phenylalanine to tyrosine ratio. J Interferon Cytokine Res 32(5):216-220 2-Kothari, C. R. (2004). Research methodology: Methods and techniques. New Age International

\section{Submit your manuscript to a SpringerOpen ${ }^{\circ}$ journal and benefit from:}

- Convenient online submission

- Rigorous peer review

- Open access: articles freely available online

- High visibility within the field

- Retaining the copyright to your article

Submit your next manuscript at $\boldsymbol{\nabla}$ springeropen.com 